\title{
Numerical Simulation of the Release of Alkali Metal during the Combustion of Biomass-fired Boiler
}

\author{
Fang Wang ${ }^{1, a}$, XianBin $\mathrm{XiaO}^{2, \mathrm{~b}}$, TengGe $\mathrm{Mi}^{3, \mathrm{c}}$, and ChangQing Dong ${ }^{4, \mathrm{~d}}$ \\ ${ }^{1}$ University of South China, Hengyang 421001, China; \\ ${ }^{2}$ National Engineering Laboratory for Biomass Power Generation Equipment, North China Electric \\ Power University, Beijing 102206, China; \\ ${ }^{3}$ University of South China, Hengyang 421001, China; \\ ${ }^{4}$ National Engineering Laboratory for Biomass Power Generation Equipment, North China Electric \\ Power University, Beijing 102206, China \\ awangfang19881024@163.com, ${ }^{b} x i a 0 x i a n b i n @ t s i n g h u a . o r g . c n, ~{ }^{c}$ mitengge@163.com, ${ }^{d}$ cqdong1@ \\ 163.com
}

Keywords: alkali metal, release, numerical simulation, biomass-fired boiler.

\begin{abstract}
In this paper, a CFD-based release model is presented to study the release process of alkali metal and predict the deposition in the furnace. In the release model, potassium chloride $(\mathrm{KCl})$ is chosen as a representative alkali. The results showed that: the concentration of $\mathrm{KCl}$, mainly releases in devolatilization and carbon combustion zone of the boiler grate, and the largest concentration appears in the carbon combustion zone. Meanwhile, the concentration of $\mathrm{KCl}$ is relatively high in superheater area. According to the simulation results, it is predicted that the right side of the three superheater regions prone to deposition and severe deposition appears on the lower turning-place of the superheater. The simulation results are in good agreement with the measured results in Heishan power plant.
\end{abstract}

\section{Introduction}

Biomass grate firing as one of the main technologies is currently widely used in biomass combustion for heat and power production. But grate-firing of some biomass fuels with a high alkali metal and $\mathrm{Cl}$ content (e.g., straw) may suffer from severe deposition and corrosion problems [1]. Therefore, to understand and master the process of biomass burning alkali metal release and transformation behavior is of big significance.

In the combustion process, the alkali metal is easy to combine with inorganic elements generating a variety of complex compounds, so it is difficult to direct study the releasing and transportation of the alkali metal during the combustion [2]. Numerical simulation of biomass combustion represents today a very useful approach, and it is much faster and cheaper than an experimental campaign [3]. In this paper, the CFD software FLUENT is used to simulate the biomass combustion process and the release of alkali metal, $\mathrm{KCl}$ is chosen as a representative alkali metal[4], an alkali metal release model is established to study the release behavior of alkali metal during the combustion.

\section{Modeling approach}

A comprehensive model for the prediction of the combustion of solid biomass is adopted, including fuel bed model, combustion model and alkali metal release model in turn [5]. The CFD prediction is carried out using Ansys-Fluent, coupled with UDF by $\mathrm{C}++$. The porous model is used to simulate fuel bed combustion. The RNG k- $\varepsilon$ model and eddy-dissipation model is chosen to simulate the gas-phase combustion. The alkali metal release law is coupled in bed porous model by UDF. Radiative heat transfer is modelled using the DO model.

Physical model. The 3D physical model of biomass-fired boiler is shown in Fig.1.There are three measure points in the furnace aiming at comparing with actual boiler operation results. The 
computation domain is discretized by using unstructured mesh to solve the mass, momentum, energy equations. The total grid is about 1300000 cells. Schematic of mesh scheme is shown in Fig.2. The fuel is wheat straw, its industrial and elemental analysis data are shown in Table 1.

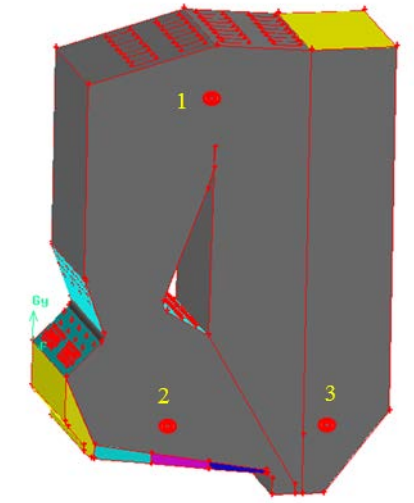

Fig.1 The 3D physical model of biomass-fired boiler

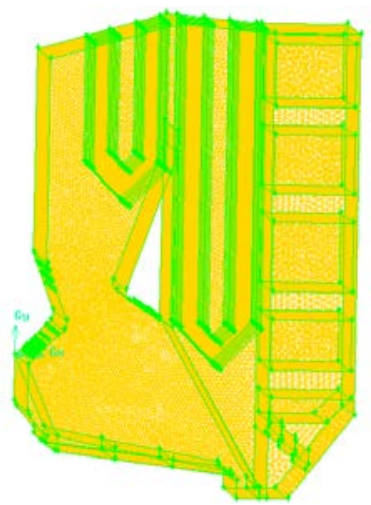

Fig.2 Schematic of mesh scheme in the furnace

Table 1 Industrial and elemental analysis of wheat straw

\begin{tabular}{cccccccccc}
\hline \multirow{3}{*}{ Wheat straw } & $\mathrm{C}^{\mathrm{y}} \%$ & $\mathrm{H}^{\mathrm{y}} \%$ & $\mathrm{O}^{\mathrm{y}} \%$ & $\mathrm{~N}^{\mathrm{y}} \%$ & $\mathrm{~S}^{\mathrm{y}} \%$ & $\mathrm{~A}^{\mathrm{y}} \%$ & $\mathrm{~W}^{\mathrm{y}} \%$ & $\mathrm{~V}^{\mathrm{y}} \%$ & $\mathrm{Q}_{\mathrm{DW}}^{\mathrm{y}} \mathrm{KJ} / \mathrm{kg}$ \\
\cline { 2 - 9 } & 38.57 & 4.83 & 34.90 & 0.426 & 0.134 & 6.137 & 15 & 69.32 & 14290 \\
\hline
\end{tabular}

Numerical model. The gas phase and solid phase conservation equations are built to calculate the flow field and temperature field. Represented by $\mathrm{KCl}$, Alkali metal release model is set up. According to the experimental results, select the study results of Lone A. Hansen as $\mathrm{KCl}$ release law[6], shown in Fig.3,the release mass fraction of $\mathrm{KCl}$ is calculated by Eq.1, where $m_{k c l}$ represents the release mass fraction of $\mathrm{KCl}(\%), t$ represents the corresponding temperature $\left({ }^{\circ} \mathrm{C}\right)$.

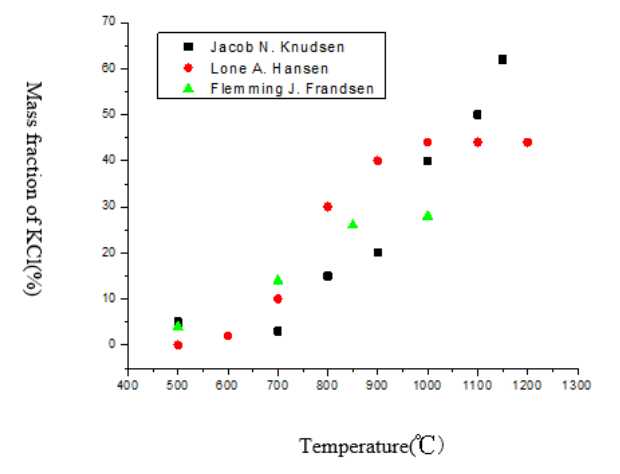

Fig.3 the main experiment results

$$
\text { of } \mathrm{KCl} \text { release law }
$$$$
m_{k c l}=\left(-4 e^{-7} t^{3}+0.001 t^{3}-0.6559 t^{2}+129.87\right) \times 8.313 \times 10^{-4}
$$

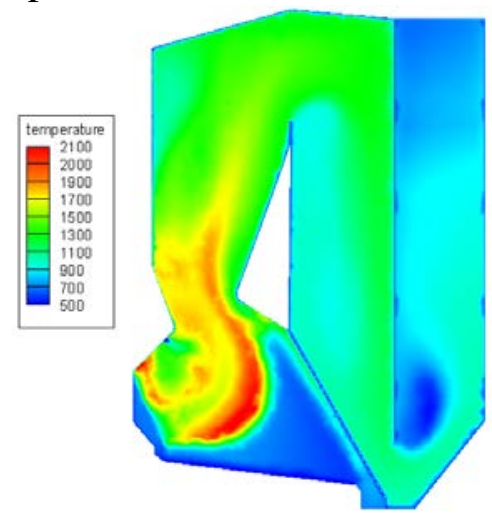

Fig.4 the temperature distribution of the central section of the furnace $(Z=2.16 \mathrm{~m})$

\section{Results and analysis}

Temperature distribution analysis. Fig.4 shows the temperature distribution of the central section of the furnace. In the alkali metal release model, the precipitated alkali metal herein assuming all of the alkali metal releases from the fuel bed area in the form of $\mathrm{KCl}$ vapor, the release amount of $\mathrm{KCl}$ is single-valued function of temperature. Therefore, getting the exact temperature field is very important. Table 2 shows the comparation of numerical calculation temperature and the experimental measuring results, the simulation results agree well with the measuring results, indicating that the choice of numerical simulation model in this paper is more reasonable. 
Table 2 Simulated temperature compared with the measured temperature

\begin{tabular}{ccccc}
\hline Measuring point & 1 & 2 & 3 & Units \\
\hline Simulated temperature & 713 & 1100 & 700 & $\mathrm{~K}$ \\
Measured temperature & 725.5 & 1077.1 & 754.5 & $\mathrm{~K}$ \\
\hline
\end{tabular}

KCl concentration field analysis.Fig. 5 shows the $\mathrm{KCl}$ concentration distribution of the central section of the furnace. As shown in Fig.5, $\mathrm{KCl}$ mainly releases from the volatiles release section and carbon combustion section of the fuel bed and the $\mathrm{KCl}$ concentration reaches the maximum concentration on carbon combustion section, while the temperature of this area is higher than other region. Fig.6 shows the $\mathrm{KCl}$ concentration distribution of the third and the fourth superheater region. As can be seen from the Fig.6, the $\mathrm{KCl}$ concentration is higher on the right side of the superheater, and the highest concentration appears on the lower turning-place of the superheater. It means that this regions prone to deposition. Fig. 7 shows the real deposition at the third superheater in Heishan biomass power plant. The forecast results of Fig.6 is in line with Fig.7, which explain that the simulation results is reliable.

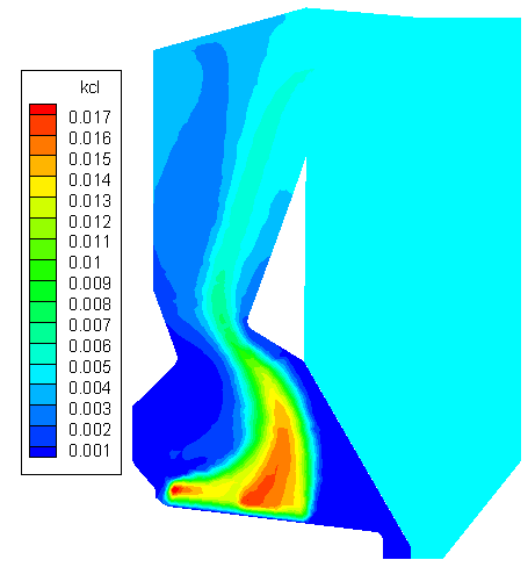

Fig. 5 the $\mathrm{KCl}$ concentration distribution of the central section of the furnace

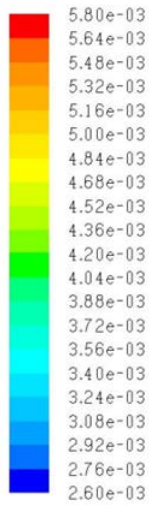

Fig. 6 shows the $\mathrm{KCl}$ concentration distribution of the third and the fourth superheater region

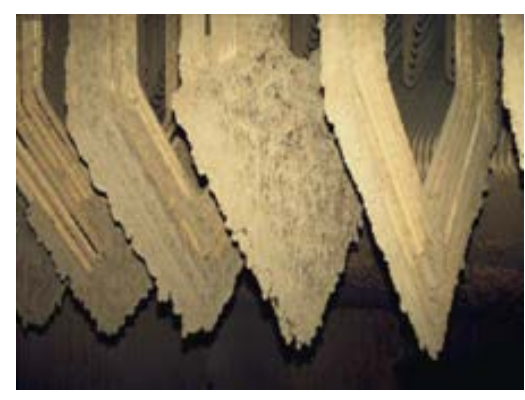

Fig.7 the picture of deposition at the third superheater

\section{Conclusions}

In this paper, a 3D full-scale combustion model is established to gain the temperature field and concentration field. $\mathrm{KCl}$ is chosen as a representative alkali metal and an alkali metal release model is established to study the release behavior of alkali metal during the combustion. The results show that $\mathrm{KCl}$ mainly releases from the volatiles release section and carbon combustion section of the fuel bed, the $\mathrm{KCl}$ concentration is higher on the right side of the superheater, and the highest concentration appears on the lower turning-place of the superheater. Based on the simulation results, it is proposed to make measures to prevent corrosion and make regularly soot blowing at 
the third superheater area in order to ensure the stable operation of the unit.

\section{Acknowledgements}

This work was financially supported by Beijing Municipal Science and Technology Project (Z131100002413008) and the Fundamental Research Funds for the Central Universities (2014ZD14).

\section{References}

[1] Chungen Yin , Lasse A. Rosendahl and Søren K. Kær, Progress in Energy and Combustion Science, 34(2008)725-754

[2] S. Kar, L. Rosendahl and L. Baxter, FUEL, 85(2006) 833-848

[3] Domenico Borello, Paolo Venturini , Franco Rispoli etal, Applied Energy, 101 (2013) 413-422

[4] FanHua Meng, TianHua Yang, Yang Sun etal, Renewable Energy, 28(2010) 111-114

[5] Søren K. Kær, FUEL, 83(2004)1183 1190

[6] Flemming J. Frandsen a, Simone C. van Lith a, Rob Korbee b, Fuel Processing Technology, 88 (2007)1118-1128 